\title{
Evaluating the efficacy of zoning designations for protected area management
}

\author{
Vanessa Hull ${ }^{\mathrm{a}, *}$, Weihua Xu ${ }^{\mathrm{b}}$, Wei Liu ${ }^{\mathrm{a}}$, Shiqiang Zhou ${ }^{\mathrm{c}}$, Andrés Viña ${ }^{\mathrm{a}}$, Jindong Zhang ${ }^{\mathrm{b}}$, \\ Mao-Ning Tuanmu ${ }^{a}$, Jinyan Huang ${ }^{c}$, Marc Linderman ${ }^{\mathrm{a}, \mathrm{d}}$, Xiaodong Chen ${ }^{\mathrm{a}, \mathrm{e}}$, Yan Huang ${ }^{\mathrm{c}}$, \\ Zhiyun Ouyang $^{\mathrm{b}}$, Hemin Zhang ${ }^{\mathrm{c}}$, Jianguo Liu ${ }^{\mathrm{a}}$ \\ ${ }^{a}$ Center for Systems Integration and Sustainability (CSIS), Department of Fisheries and Wildlife, Michigan State University, East Lansing, MI 48823, USA \\ ${ }^{\mathrm{b}}$ State Key Laboratory of Urban and Regional Ecology, Research Center for Eco-Environmental Sciences, Chinese Academy of Sciences, Beijing 100085, China \\ ${ }^{\mathrm{c}}$ China Conservation and Research Center for the Giant Panda (CCRCGP), Wolong Nature Reserve, Sichuan 623006, China \\ ${ }^{\mathrm{d}}$ Department of Geography, The University of Iowa, Iowa City, IA 52242, USA \\ ${ }^{\mathrm{e}}$ Department of Geography, The University of North Carolina at Chapel Hill, Saunders Hall, Campus Box 3220, Chapel Hill, NC 27599, USA
}

\section{A R T I C L E I N F O}

\section{Article history:}

Received 7 August 2011

Received in revised form 13 September 2011

Accepted 19 September 2011

Available online 27 October 2011

\section{Keywords:}

Giant panda

Protected area

Zoning

Conservation

Development

\begin{abstract}
A B S T R A C T
Protected areas worldwide are facing increasing pressures to co-manage human development and biodiversity conservation. One strategy for managing multiple uses within and around protected areas is zoning, an approach in which spatial boundaries are drawn to distinguish areas with varying degrees of allowable human impacts. However, zoning designations are rarely evaluated for their efficacy using empirical data related to both human and biodiversity characteristics. To evaluate the effectiveness of zoning designations, we developed an integrated approach. The approach was calibrated empirically using data from Wolong Nature Reserve, a flagship protected area for the conservation of endangered giant pandas in China. We analyzed the spatial distribution of pandas, as well as human impacts (roads, houses, tourism infrastructure, livestock, and forest cover change) with respect to zoning designations in Wolong. Results show that the design of the zoning scheme could be improved to account for pandas and their habitat, considering the amount of suitable habitat outside of the core zone (area designated for biodiversity conservation). Zoning was largely successful in containing houses and roads to their designated experimental zone, but was less effective in containing livestock and was susceptible to boundary adjustments to allow for tourism development. We identified focus areas for potential zoning revision that could better protect the panda population without significantly compromising existing human settlements. Our findings highlight the need for evaluating the efficacy of zoning in other protected areas facing similar challenges with balancing human needs and conservation goals, not only in China but also around the world.
\end{abstract}

(c) 2011 Elsevier Ltd. All rights reserved.

\section{Introduction}

Human activities have caused massive losses in Earth's biodiversity over the last few centuries in what has been termed "the sixth extinction" (Leakey and Lewin, 1996). The current rate of extinctions attributed to humans is markedly above background rates observed in the fossil record (Barnosky et al., 2011). The underlying causes of this phenomenon lie in the cascading effects of anthropogenic activities such as habitat destruction, overharvesting, invasive species, and greenhouse gas emissions (Diamond,

* Corresponding author. Address: Center for Systems Integration and Sustainability (CSIS), Michigan State University, 1405 S. Harrison Road, Suite 115 Manly Miles Bldg., East Lansing, MI 48823-5243, USA. Tel.: +1 517432 5025; fax: +1 517 4325066.

E-mail address: hullvane@msu.edu (V. Hull).
2005; Pimm et al., 1995). Today, few ecosystems are untouched by humans, such that they can be conceptualized as coupled human and natural systems (CHANS) in which the human and natural components are intricately linked (Liu et al., 2007b). Appreciating the interactions, feedbacks, heterogeneity, thresholds, and surprises that arise in CHANS helps to better understand, model, and derive management recommendations for complex systems across the globe (Liu et al., 2007a).

Alarming trends in ecosystem degradation have inspired multifaceted conservation initiatives over the last few decades, one of the most salient being the establishment of protected areas, or set aside areas for biodiversity conservation where human activities are limited or controlled (DeFries et al., 2007). There are now over 100,000 protected areas across the world, covering nearly $13 \%$ of the global land area (Jenkins and Joppa, 2009; WDPA, 2009). Success of protected areas in achieving conservation goals 
has been mixed, as not all have been able to function effectively in an increasingly human dominated world (Andam et al., 2008; Babcock et al., 2010; Liu et al., 2001; Wittemyer et al., 2008).

Over the last two decades, there has been a noticeable shift in the design and conceptualization of protected areas across the world (Naughton-Treves et al., 2005). Once seen as areas of pristine wildlife habitat where no human impacts should be allowed, protected areas are now increasingly designated as areas where multiple-use activities occur which include, but are not limited to, biodiversity conservation (Geneletti and van Duren, 2008; Gonzales et al., 2003; Naughton-Treves et al., 2005). This shift occurred as a result of both the recognition of the reality of increasing human presence in once untouched ecosystems and the realization of the ethical dilemma involved in removing basic resource access rights to rural poor communities living in biodiversity hotspots (Naughton-Treves et al., 2005).

Because the Earth has become occupied by increasingly industrialized societies, there is a lack of space available worldwide to accommodate all goals and there is a need to more strategically designate the spatial extents of competing activities. The increasing prevalence of multiple-use protected areas across the globe has prompted managers to initiate careful design strategies founded upon zoning schemes that designate specific areas along a gradient from fully off-limits to humans to fully-available for multiple human activities (Geneletti and van Duren, 2008). Zoning is increasingly being used in design of one of the most common types of protected areas- nature reserves. Zones may be set up as part of larger-scale biodiversity planning over areas that encompass a number of once singularly-managed small nature reserves, with areas bordering reserves designated as buffers between reserves and neighboring human development zones (Eigenbrod et al., 2009). It has been argued that in an increasingly humandominated world, zoning designations serve an important purpose in mitigating conflicts between competing uses for limited resources by establishing guidelines for multiple use of shared space (Hjortso et al., 2006; Sabatini et al., 2007).

Zoning has featured prominently throughout the scientific literature on protection of marine reserves for designation of specific areas for varying levels of fishing or recreation in diverse ocean systems across the world (Agardy, 2010). Surprisingly, discussions on zoning are less prominent in comparable literature on terrestrial reserves (Geneletti and van Duren, 2008). Across both terrestrial and marine systems, a variety of tools have been developed to design zoning schemes, such as Marxan-based decision support tools (Watts et al., 2009), simulated annealing (Sabatini et al., 2007), and spatially-explicit ecosystem-based tools (Salomon et al., 2002). However, there are much fewer examples of empirical studies investigating the efficacy of existing zoning schemes, such as recent studies on the marine ecosystem in the Great Barrier Reef Marine Park (Kenchington and Day, 2011) and large mammals in a Central African protected area system (Remis and Kpanou, 2011).

The main criticism of zoning is that there is no clear mechanism to operationalize it on the ground. Thus, zoning designations often become "paper maps" that exist in management plans but have no meaning with respect to realized activities (Sabatini et al., 2007). This can occur especially in developing nations, where protected areas lack funding and personnel to design and enforce guidelines about proper activities for each designated zoning area (Sabatini et al., 2007).

Challenges in designing and enforcing zoning schemes are particularly significant in China, the world's fastest growing economy during the past three decades that also has seen explosive growth in the number of nature reserves (Liu and Raven, 2010; State Forestry Administration, 2006). Nature reserves in China are set up such that many encompass areas already inhabited by rural human communities (Jim and $\mathrm{Xu}, 2002$ ). The presence of humans in and around the protected areas has often threatened their effectiveness, in some cases causing ecosystem decline despite the protected status (Harris, 2008; Liu et al., 2001). Faced with the challenge of balancing development and conservation needs, the government mandated that all nature reserves in China be divided into three zones: core, buffer, and experimental (The State Council, 1994). This scheme appears to be largely inspired by the same configuration initiated by UNESCO and the IUCN for biosphere reserves, areas of regional-based management of resources that bisect human and natural areas and are designed to promote both biodiversity conservation and sustainable development (Batisse, 1997; McNeely, 1994). The core zone is designed to protect natural ecosystems and the experimental zone is set up to allow for human development, with the buffer zone positioned in-between the two in order to soften the impacts of humans on natural ecosystems (McNeely, 1994; Yu and Jiang, 2003).

In practice, however, many reserves in China have not followed this mandate, considering that some reserves lack buffer zones, while others place buffer zones in locations that are not in-between the core and experimental zones (thus defeating their purpose) (Liu and $\mathrm{Li}, 2008$ ). Even some reserves that do follow the specified 3-zone framework do not design the zones according to the stated conservation goals, because the designations are based solely on proximity to human settlements, as opposed to wildlife habitat quality or suitability (Jim and Xu, 2004; Liu and Li, 2008). In addition, the mandate may actually induce further environmental degradation, as some reserves with no human populations within their borders have designated an experimental zone for future development (Liu and Li, 2008). Spatial context of zoning that extends beyond individual protected areas is also not adequately considered, as the core zone of one reserve may not be contiguous with core zones of neighboring reserves (Xiao et al., 2011).

Furthermore, there has not been a concerted attempt to evaluate the efficacy of existing zoning designations in China's reserves for meeting their intended goals of balancing human activities with biodiversity conservation. Here we attempt to fill this gap using the world-renowned Wolong Nature Reserve, as a case study. Wolong is an ideal case study for examining this issue because it is a flagship nature reserve that other protected areas across China look to as an example when shaping future policy (Liu et al., 2001). We specifically focused on the effectiveness of the zoning scheme for this reserve with respect to conserving the endangered giant panda (Ailuropoda melanoleuca, TSN: 621845), an animal revered as a national treasure for which more than 60 nature reserves have been established across its geographic range (Viña et al., 2010). The panda is ideal for such an analysis because it is a flagship species that garners significant conservation attention (Liu et al., 2001) and may also be considered an umbrella species, since its habitat encompasses areas with among the greatest biodiversity per unit area in the world (Mackinnon, 2008). We analyzed the spatial distribution of both pandas and human impacts across the different zoning designations in the reserve. We then proposed adjustments of the zoning boundaries that would better meet giant panda conservation needs without significantly compromising existing human settlements. We discuss the role of zoning in the greater toolbox of conservation approaches and explore the implications of the findings for protected areas across the world that face similar and growing challenges of balancing human needs and biodiversity conservation.

\section{Materials and methods}

\subsection{Study area}

The study area is Wolong Nature Reserve $\left(102^{\circ} 52^{\prime}-103^{\circ} 24^{\prime} \mathrm{E}\right.$, $30^{\circ} 45^{\prime}-31^{\circ} 25^{\prime}$ N, Fig. 1), Sichuan, China. Established in 1975 , the 

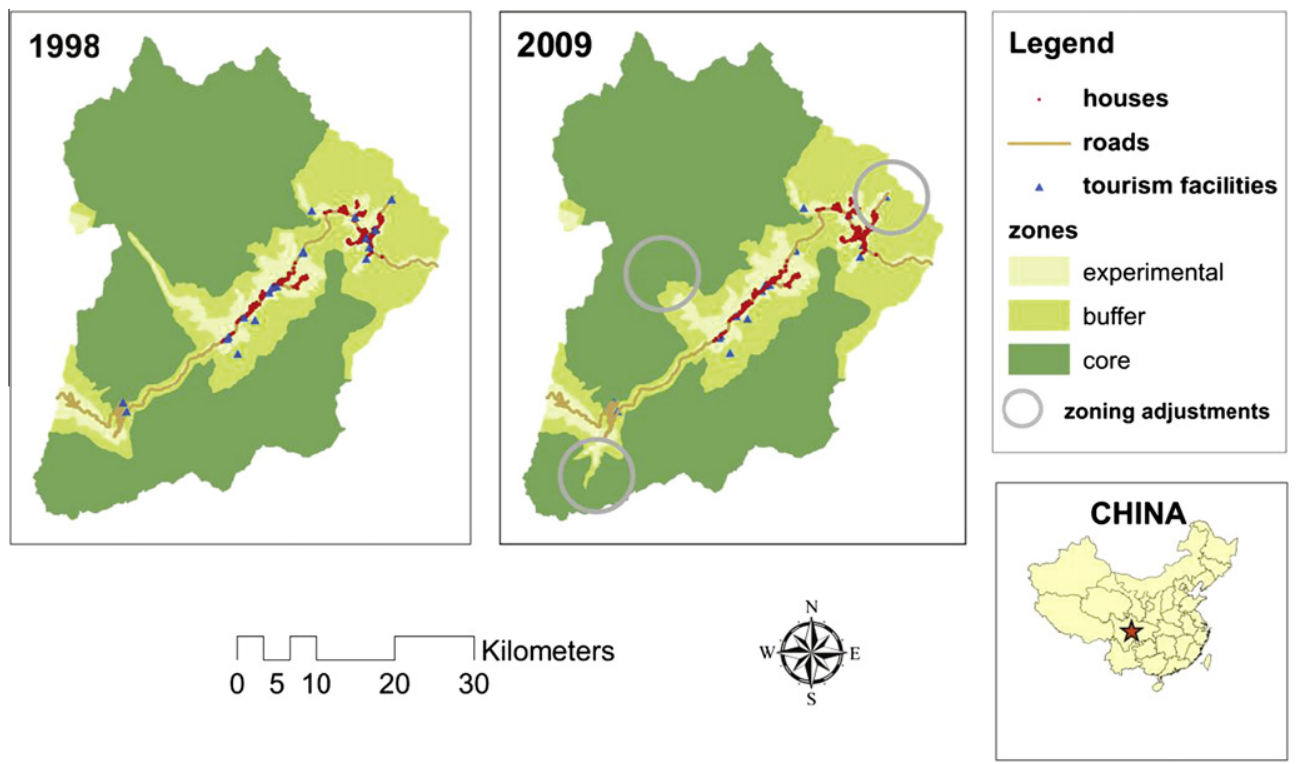

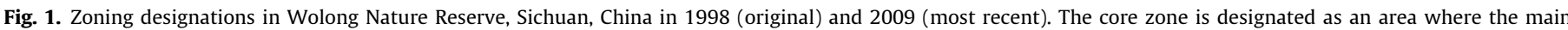

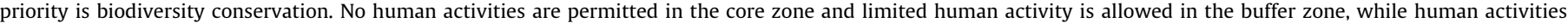
(including infrastructure development) are permitted in the experimental zone.

reserve consists of a $2000 \mathrm{~km}^{2}$ area that supports approximately $10 \%$ of the total giant panda population (Zhang et al., 1997). Aside from giant pandas, there are over 2200 animal species and around 4000 plant species that are found within the reserve (Tan et al., 1995), a high level of biodiversity that is related to the large elevation range spanning $1200-6250 \mathrm{~m}$ (Schaller et al., 1985). The topography in the reserve is characterized by steep cliffs alternating with narrow valleys, with slopes exceeding $50^{\circ}$ in some places (Schaller et al., 1985). At the elevation ranges where giant pandas are most commonly found (2000-3300 m), the habitat consists of mixed coniferous and deciduous broad-leaved forest and subalpine coniferous forest (Schaller et al., 1985).

There are also nearly 5000 local residents living within the reserve. The residents are mostly ethnic minorities of predominantly Tibetan (in addition to Qiang) descent who partake in farmingbased lifestyles (Ghimire, 1997). The residents interact with the natural environment in ways that impact the giant pandas and their habitat, mainly via land cultivation, animal husbandry, timber harvesting, fuelwood collection, and medicinal herb collection (Liu et al., 1999; State Forestry Administration, 2006). There is also a provincial-level road running through the reserve (303) which supports various forms of transportation of goods and people, and in so doing fuels the local economy.

The reserve is managed under the Wolong Administration Bureau, which is presided over by both the State Forestry Administration and the Sichuan provincial-level government. The earliest zoning scheme for Wolong was conceptualized in the late 1970s, as reserve officials differentiated between two distinct regulatory zones - one for human development and one for protection of nature (Wolong Nature Reserve, 2005). The regulation called for the complete relocation of one of the villages in an attempt to contain human development, a part of the plan which never materialized (Ghimire, 1997). A more integrated version of the zoning scheme was later formalized as part of the "Wolong Nature Reserve Master Plan" released in 1998. The zoning scheme is designed to help achieve the objectives of the Reserve, which were first identified as focused "mainly [on] the protection of [the] giant panda, other valuable rare animals and plants, and the typical natural ecosystem there" (Ministry of Forestry, 1998, p. IX) in addition to "meet[ing] the country's modernization construction and sustainable develop- ment strategies" (Ministry of Forestry, 1998, p. X). The zoning scheme includes the core, buffer, and experimental zones according to the national guidelines for reserve planning. No human activity is permitted in the core zone and limited (but not clearly defined) human activity is allowed in the buffer zone, while human development is allowed in the experimental zone. While the specific methodology behind zoning boundary designation is not explained in the plan, the factors that went into zoning considerations included tourism, agriculture, distance to roads, elevation, wildlife, vegetation, scientific research activities and "specific regulatory rules" (Ministry of Forestry, 1998). Parameters were assigned to $2 \times 2 \mathrm{~km}$ cells drawn across the reserve with respect to each factor and were then combined in a clustering algorithm to generate the final zoning designations (Ministry of Forestry, 1998) (Fig. 1).

The zoning designation was largely based upon proximity to the provincial road that cuts through the reserve. The provincial road outlines areas where human development has already taken place and will be permitted to continue (mainly areas closest to the road). In the original zoning designation, the majority of the reserve consisted of core zone $\left(1416 \mathrm{~km}^{2}, 70 \%\right.$ of total), followed by buffer $\left(434 \mathrm{~km}^{2}, 21 \%\right.$ of total), and experimental $\left(183 \mathrm{~km}^{2}, 9 \%\right.$ of total, Fig. 1). The buffer zone located in between the core and experimental zones was notably narrow in some places, with $23 \%$ of the distances in between the core and experimental zones being less than $500 \mathrm{~m}$.

There have been minor adjustments to the zoning boundaries in Wolong over the years, but the overall shape and distribution remains the same (Fig. 1). A revised zoning scheme was drawn up after the May 12, 2008 Wenchuan Earthquake in order to account for post-earthquake reconstruction, with all reconstruction designated to be contained in the experimental zone. The revisions resulted in little change from the original, with only a $0.4 \%$ decrease in buffer zone and $0.4 \%$ and $0.2 \%$ increases in experimental and core zones, respectively. These changes amounted to slight revisions in zoning designations at three locations throughout the reserve (Fig. 1). One change involved the conversion of a long valley from experimental to core zone after tourism development was deemed infeasible (middle circle), while two other changes involved a slight extension of buffer and experimental zones to allow 
for planned future tourism development (right and left-most circles). Unless otherwise stated, we used the original 1998 version for analysis in the study, as it is the one that has been operational for the majority of the time period evaluated.

\subsection{Zoning and pandas}

The distribution of pandas with respect to the zoning scheme in Wolong was evaluated using three complementary approaches: (1) assessment of panda habitat suitability across zones, (2) spatial overlay of panda census data (derived from fecal counts obtained during transect surveys) and zones, and (3) summary of behavior of two individual GPS-collared giant pandas with respect to zones. The three different approaches were used in order to strengthen the assessment of the relationship between zoning designations and pandas, considering that each approach has different strengths and limitations. The first approach (habitat suitability index) is informative in that it provides a broad-scale assessment of potential habitat. The second approach (panda census) is a more direct measure of panda habitat use than the first and comprises the most comprehensive dataset in existence on panda distribution across the reserve. The third approach (GPS collar study) captures the behavior of individual pandas in a temporally-explicit way that has rarely been demonstrated before. Together, the three approaches provide a comprehensive picture of panda distribution with respect to the zones.

For the first approach, we used a giant panda habitat suitability index established by Liu et al. (1999) and reported in Liu et al. (2001). This index was a multiplicative function of three main environmental variables (elevation, slope, and forest) that contribute to habitat suitability for pandas. Specifically, pandas prefer gentle slopes, moderate elevation ranges and forested areas (Liu et al., 2001). Elevation and slope were derived from a digital elevation model (DEM) of Wolong $(90 \times 90 \mathrm{~m}$ resolution), while forest was derived from land cover classifications of Landsat Thematic Mapper (TM) images $(30 \times 30 \mathrm{~m}$ resolution) acquired in 1997 (pre-zoning) (Liu et al., 2001; Viña et al., 2007). We summarized habitat suitability index by zone by determining the percentage of pixels in each habitat suitability class in each zone.

For the second approach, we used data from the 3rd National Giant Panda Census, the most recent comprehensive evaluation of the distribution of giant pandas across their geographic range, which was conducted from 2000 to 2004 (State Forestry Administration, 2006). We used all observed locations of panda signs from the survey that took place in Wolong (in May and June of 2001), which represent observations of panda presence (but are not tied to individual pandas, $n=487$ ). This is the only comprehensive dataset for panda distribution available across the entire Reserve and it is currently the standard used for panda management assessment and decision making by central, provincial and local governments. This dataset is likely biased to more accessible areas that are easier to search. In other words, there was probably a higher proportion of the experimental and buffer areas searched for panda signs as opposed to the more remote core areas. To roughly define the known distribution pattern of giant pandas in the reserve, we generated a bivariate normal kernel density contour (Bailey and Gatrell, 1995) (bandwidth $h=1000 \mathrm{~m}$ ). The kernel allowed us to delineate a polygon with a boundary encompassing $95 \%$ of the panda signs. We chose the $95 \%$ contour because it would provide a conservative estimate of habitat use while capturing the majority of the distribution area. A spatial overlay was conducted to determine the density of panda signs found within the portion of the kernel in each of the zoning designations (number of panda signs divided by the kernel area).

For the third approach, we used data acquired by global positioning system (GPS) collars (12-channel GPS_4400M, Lotek Engi- neering Inc., Newmarket, Ont., Canada) placed on two wild, female pandas (Mei Mei and Pan Pan) in Wolong. Although this is a small sample size, this is one of the first GPS collar studies and one of the first panda tracking studies done on the species since radio tracking studies were conducted in the 1980s and early 1990s. We obtained special permission to collar only a small number of pandas, marking the end of a 15 year-long government-enforced ban on all telemetry of giant pandas. The collars were programmed to collect GPS fixes every $4 \mathrm{~h}$ during the period of April 18, 2010 to April 12, 2011 (Mei Mei) and April 18, 2010November 25, 2010 (Pan Pan, had a shortened time frame since collar fell off). We used data acquired at least 1 week after the pandas were collared, in order to reduce bias from the possible effect of the collaring event on panda behavior. Fix acquisition rates of the collars were $44 \%$ and $40 \%$, for Mei Mei and Pan Pan, respectively. Considering the short dispersal distances for this species (normally less than $500 \mathrm{~m}$ straight distance a day), we do not believe that loss of fixes created a bias with respect to spatial distribution across zones. Field testing against a differentially-corrected GPS unit revealed that the locations recorded by the GPS collars were $95 \%$ accurate within a distance of $60 \mathrm{~m}$. The locations from the collars were overlayed with zoning designations and summarized with respect to presence inside, as well as distance from the nearest zone. The area where the pandas were found was not influenced by the zoning adjustments that occurred in the Reserve and was also not significantly influenced by the earthquake that occurred in the area in 2008.

\subsection{Zoning and human impacts}

Human impacts were analyzed with respect to the zoning designations in Wolong by characterizing (a) human activities and (b) forest cover dynamics across space. We adopted a spatial overlay framework for the majority of the analysis because we felt this approach would best integrate the available human and panda-related data with the spatial configuration of the zones. This analysis provided a means to evaluate the suitability of the design of the zoning scheme (spatial component), but also in some instances provided a means to evaluate the effectiveness of zones once put in place (temporal component). Human activities included roads, houses, tourism facilities, and livestock. Forest cover dynamics were analyzed with respect to forest cover change over time (which could reflect a combination of timber harvesting, fuelwood collection, forest monitoring, reforestation, and afforestation).

With regard to human activities, any paved surface accessible to four-wheeled vehicles was considered a road. Roads were all established prior to the zoning designation and no new roads have been built since then. Houses were drawn from the 2001 Wolong household survey (to be generally consistent with 1998 zoning designations) and house locations were recorded using a GPS unit in 2002. We also analyzed data on house locations from 2006 as a second post-zoning time point to determine whether houses were effectively contained within the experimental zone over time. Tourism facilities included any infrastructure built for tourism activities (which were all built after the zoning designation in 1998). We obtained georeferenced locations of each type and calculated the percentage of roads, houses, and tourism facilities located in each zone. We also calculated the distance of each house, tourism facility, and $100 \mathrm{~m}$ stretch of road to the nearest core zone using the Proximity Tool in ArcGIS 9.2 (ESRI, 2006).

Livestock was assessed post-zoning only using three domestic horse herds owned by local residents and maintained in three separate areas in the Reserve. While this constitutes a small snapshot of the effects of livestock across the reserve, we illustrate it here as a case study to inspire further inquiry. The herd monitored most intensively (Herd $1, n=22$ ) was monitored from July 2010 to April 
2011 using a GPS collar fitted on a member of the herd. A second herd (Herd 2, $n=15$ ) was monitored in the same manner for a shorter period from June 2011 to July 2011. The collars were identical to those used on the pandas (see Section 2.2 for collar description). The third herd (Herd $3, n=16$ ) was monitored by field surveys only, through the establishment of five transects running through a roughly $1 \mathrm{~km}^{2}$ area where we observed them to roam over the previous 1 year period. We recorded the presence or absence of any horse sign (feces or eaten bamboo) in $30 \times 30$ m plots every $100 \mathrm{~m}$ along these transects. We then summarized percentage of GPS points (Herds 1 and 2) or field plots with horse presence (Herd 3) across zones.

With respect to forest cover change, Landsat TM images of the reserve in 1974, 1997, and 2007 were classified into forest and non-forest covers using supervised and unsupervised classification approaches (for details see: Linderman et al., 2005; Liu et al., 2001; Viña et al., 2007). The year 1974 was the year prior to the Reserve establishment and the year 1997 was the year prior to the zoning designation. We included the 1974 time point in order to provide historical context for forest cover dynamics in this reserve and across the as-yet undesignated zones. Previous studies have shown marked declines in forest cover in Wolong from 1974 to 1997 and then some degree of recovery after 2001 (Liu et al., 2001; Viña et al., 2007, 2011). Recent recovery is associated with the implementation of two conservation/restoration programs: the Natural Forest Conservation Program (NFCP) and the Grain-to-Green Program (GTGP) (Viña et al., 2011). However, these changes have not been analyzed with respect to differences across zones. We analyzed forest change across zones by performing a spatial overlay of zoning designations and forest cover.

\subsection{Proposed zoning revisions for panda conservation}

We set out to identify areas in the current zoning scheme that could be redrawn for the specific purpose of improving the conservation of the endangered giant panda. We used the $95 \%$ kernel of panda signs obtained from the latest panda census (generated in Section 2.2) to represent the main area occupied by pandas in the reserve (panda presence layer). We chose to use the kernel for the panda presence layer as opposed to the actual census points because we believe that the buffered region around known panda locations helped to account for potential movement of the animals over space. We then generated a corresponding spatial extent for human establishments in the Reserve (human presence layer). To create this human presence layer, we combined spatial locations of roads, tourism facilities, and houses with buffers of different distances around them. We created a $200 \mathrm{~m}$ buffer around all roads, which matched the width of the experimental zone along the road in the existing zoning designation. This distance seemed reasonable because in the case where roadsides were not lined by existing human establishments, the steepness of mountainsides on either side of the road made human presence drop off over short distances. We chose a larger buffer of $500 \mathrm{~m}$ around tourism facilities and households to account for activities such as farming and infrastructure development that could comprise larger areas.

We then overlayed the panda presence layer, the human presence layer, and the zoning boundaries layer (in this one instance we used the most recent 2009 version). The main purpose of proposing a potential revision was to identify specific areas of experimental and buffer zone that were contained within the panda presence layer but currently outside of the human presence layer. In other words, we sought to identify areas that could be better protected by the zoning designation (i.e., converted from experimental to buffer or buffer to core) for panda conservation without significantly compromising existing human settlements.

\section{Results}

\subsection{Zoning and pandas}

The zoning scheme in Wolong was not distributed in a way that maximized protection of the endangered giant panda in the core zone. During 1997 (the year prior to zone designation), around $54 \%$ of highly suitable habitat laid outside the core zone ( $40 \%$ in the buffer and $14 \%$ in the experimental zones, Fig. $2 \mathrm{a}$ ). A similar distribution across zones was found for suitable panda habitat (47\%, $41 \%$, and $12 \%$ in core, buffer, and experimental zones, respectively). The core zone contained a high percentage of unsuitable habitat (comprising 78\% of all unsuitable habitat). The reason for this distribution is that the core zone included a large area of high elevation, i.e., non-forested areas above the tree line that are not considered panda habitat. If we isolate just the elevational range at which pandas are primarily found (2000-3300 m) (Schaller et al., 1985), we find that the remaining unsuitable habitat is more evenly distributed across zones (Fig. 2b). However, the overall pattern of distribution of habitat suitability classes remains otherwise the same, with a considerable amount of suitable habitat existing outside of the core zone.

The data on panda occurrence supports the general pattern of pandas being not limited to just the core zone. The panda presence data obtained from the 3rd National Giant Panda Census (State Forestry Administration, 2006) showed that 58\% of panda signs were found in the core, $38 \%$ in the buffer, and $5 \%$ in the experimental zone (Fig. 3). Considering the kernel representing estimated panda distribution area in Wolong, there was nearly equal density of panda signs found in the core and buffer zones (1.03 and 1.01 signs per
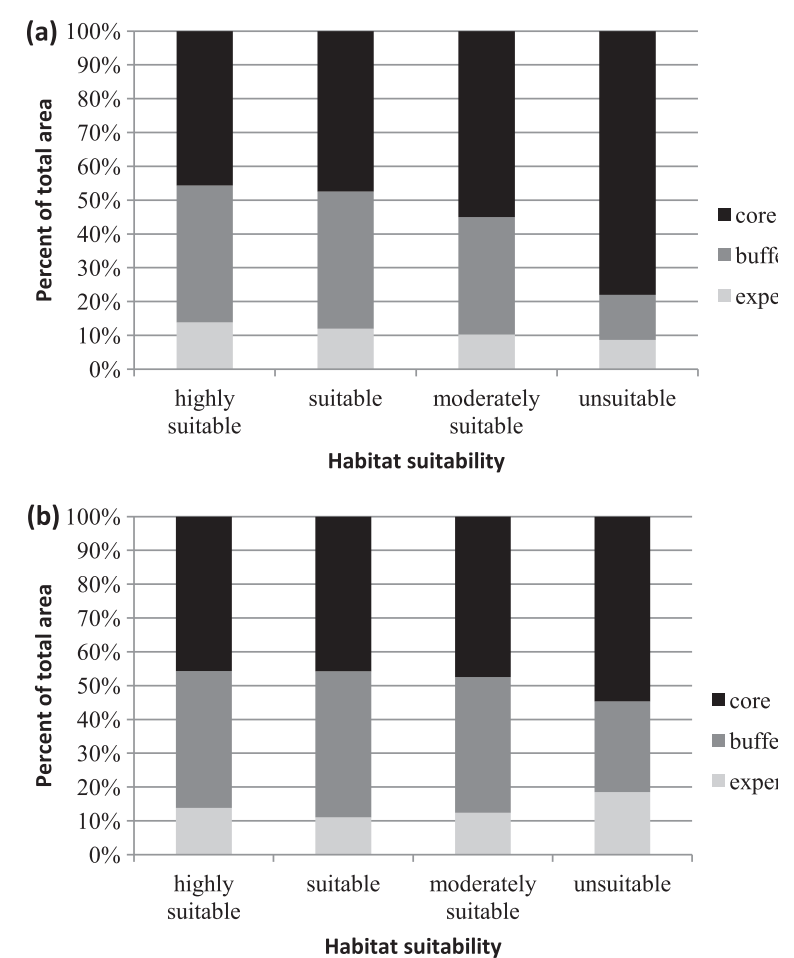

Fig. 2. Distribution of giant panda habitat suitability classes across core, buffer, and experimental zones in Wolong Nature Reserve in 1997 (year before zoning designation). Habitat suitability was derived from the criteria established in Liu et al. (1999) and reported in Liu et al. (2001), which considers panda habitat as a combination of suitable slopes, elevations (both derived from a DEM) and forest cover (derived from Landsat imagery). Distribution is shown for (a) the entire reserve and (b) only the portions of the reserve within the giant panda's elevational range $(2000-3300 \mathrm{~m})$. 


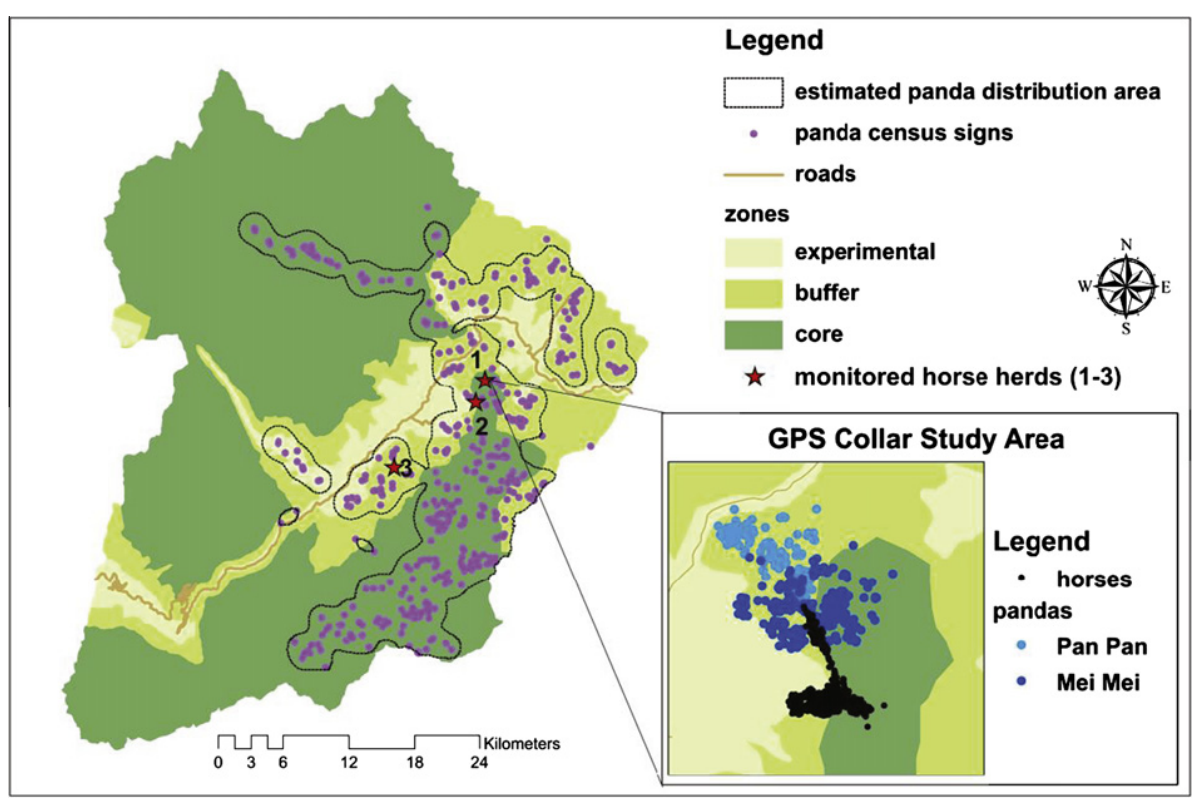

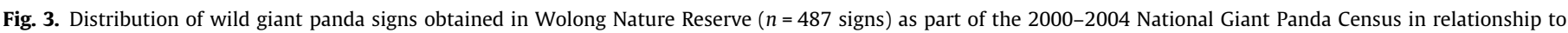

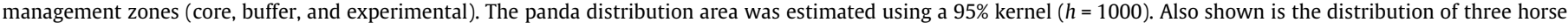
herds monitored. Inset map shows a GPS collar study on two wild giant panda females (Mei Mei and Pan Pan) and one of the horse herds.

$\mathrm{km}^{2}$ ), with about half the density in the experimental zone $\left(0.46\right.$ signs per $\left.\mathrm{km}^{2}\right)$.

With respect to the GPS-collared pandas, both pandas were also not limited to the core zone and in fact spent most of the time in the buffer zone (Fig. 3, inset map). Mei Mei had 58\% of fixes in the buffer zone, $32 \%$ in the core zone, and $1 \%$ in the experimental zone. There was not a particular time of year that she preferred the buffer over the core zone, as she used both intermittently. The boundary between the core and buffer zone happened to run down the center of her roughly $3 \mathrm{~km}^{2}$ range for the time period in question (the boundary lay along a valley bottom and Mei Mei split her time along mountainsides on both sides of the valley). Mei Mei's use of the experimental zone occurred because her range was buttressed up against a livestock grazing area (which formed the outer boundary of the experimental zone). Pan Pan spent no time in the core zone during the course of the study, while $99 \%$ of her fixes were located in the buffer zone and $1 \%$ in the experimental zone. Pan Pan's use of the experimental zone occurred when she was distributed at a lower elevation, a mere one hundred meters of map distance to the main road during a time in which the low elevation umbrella bamboo (Fargesia robusta) shoots were emerging. In both pandas the $1 \%$ use of experimental zone occurred very close to zone boundaries and could be interpreted as resulting from errors in the GPS collar or the zoning map. Nonetheless, the close proximity to experimental zone is of importance. In fact, Mei Mei and Pan Pan were located on average $912 \pm 470 \mathrm{~m}$ and $940 \pm 531 \mathrm{~m}$ (mean $\pm \mathrm{SD}$ ) from the nearest experimental zone, respectively.

\subsection{Zoning and human impacts}

Zoning had mixed results with respect to containing human activities in the experimental zone (Fig. 4). Houses were completely contained within the experimental zone (during both 2002 and 2006). Roads and tourism facilities were mostly contained within the experimental zone ( $87 \%$ and $79 \%$, respectively). Tourism facilities were distributed closest to the core zone $(63 \%$ within $1 \mathrm{~km}$ ), followed by roads (53\% within $3 \mathrm{~km}$ ) and houses (68\% within $4 \mathrm{~km}$, for map see Fig. 1 ).
Of the four tourism facilities located outside the experimental zone, two of the three sites in the buffer zone included a long-term scientific monitoring station that is occasionally inhabited by controlled (and minimal) numbers of birders and a recently constructed panda observation station for tourists that is no longer used as a result of the May 12, 2008 Wenchuan earthquake. The third site in the buffer zone was a major tourism attraction currently in construction, which required a revision in zoning, such that the 2009 zoning scheme now designates the area as experimental zone. The one site located in the core zone was a scenic destination along the small portion of the main road which falls inside the core zone, although in a high elevation, non-forested area that does not constitute giant panda habitat. We believe this portion of road was misclassified due to the use of an inaccurate provincial road layer during the zoning designation.

In contrast to the houses, roads, and tourism facilities, livestock were not well contained in the experimental zone (Fig. 4). Herd 1 (the herd monitored over the longest time period) spent most of its time in the buffer zone (52\%) followed by the core $(33 \%)$ and

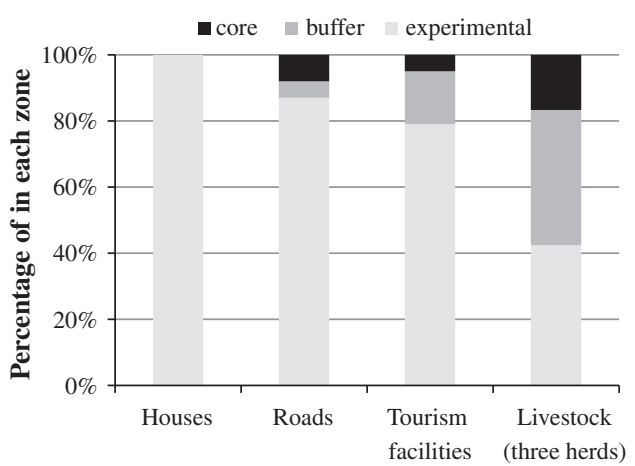

Human activity

Fig. 4. Percentage of houses, roads, tourism facilities, and livestock in each management zone (core, buffer, and experimental) in Wolong Nature Reserve. House locations $(n=1060)$ were measured with GPS units in 2002, roads were obtained from government documents, tourism facilities $(n=19)$ were recorded with GPS units in 2006, and livestock (three herds of horses only) were monitored using GPS collars and field sampling. 
experimental (15\%) zones. There was not a particular time of year that the herd was found in one zone or another. Instead, the herd was located over a roughly $2-3 \mathrm{~km}^{2}$ region where the buffer zone was particularly narrow (100 m wide at the narrowest point) and thus the herd would migrate freely back and forth through core, buffer, and experimental zones all within a span of $500 \mathrm{~m}$ and often spend parts of a single day in more than one zone (Fig. 3, inset map). Herd 2 was distributed in a roughly $0.17 \mathrm{~km}^{2}$ area between experimental (70\%) and buffer (30\%) zones during the short time (1 month) it was monitored. All horse signs spanning the distribution of Herd 3 were distributed solely in the buffer zone (100\%) across a $0.8 \mathrm{~km}^{2}$ area roughly $1.5 \mathrm{~km}$ away from both the nearest experimental and core zones.

Forest cover change also varied across zones (Fig. 5). The forest cover loss that occurred from 1974 to 1997 (both periods prior to zoning designation) was highest in the area that would later be designated the experimental zone, followed by the buffer and core zones. At the time of designation, the core zone inherently had the lowest forest cover (30\%) compared to buffer (62\%) and experimental (44\%) due to the fact that this contained large areas at high elevations and above the tree line. After zoning designation, both the buffer and core zones experienced forest recovery such that the

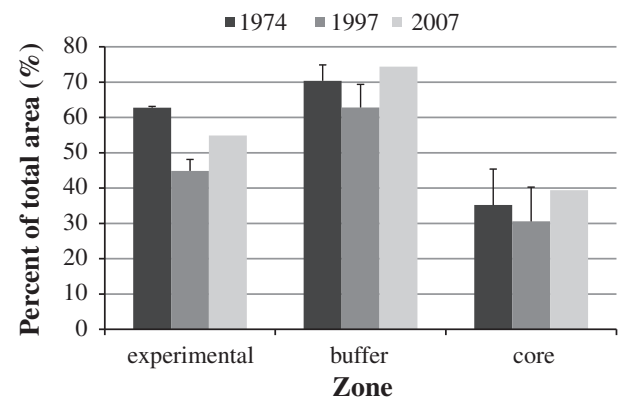

Fig. 5. Forest cover across zoning designations in Wolong Nature Reserve in 1974 (year before reserve establishment), 1997 (year before zoning designations), and 2007. Forest cover was derived from Landsat TM imagery and analyzed with respect to areal coverage in each zone. Error bars on the forest classification of the 1974 and 1997 images represent the area taken up by "unclassified" areas (areas with excessive clouds) that could have either been forest or non-forest. resulting percent forest cover exceeded the estimated percentage once existing in 1974 by around $4 \%$. On the other hand, the forest recovery in the experimental zone during the 1997-2007 period, while nearly equivalent in overall magnitude to the other two zones ( $\sim 12 \%$ ), did not have as measurable of an impact when considering its potential for supporting forest, since the forest cover in this zone remained 8\% lower than it once was in 1974.

\subsection{Proposed zoning revisions for panda conservation}

We identified approximately $37 \mathrm{~km}^{2}$ of current experimental zone in the reserve that is outside of existing human establishment but also inside of areas identified as having panda presence (focal experimental zone, Fig. 6). These areas are identified here as deserving consideration for future adjustment to become either buffer or core zone (or a combination of the two). Three of these areas deserve mention (A-C in Fig. 6). Areas A and B are both valleys that have apparently been left open as experimental areas for potential tourism development in the future. Area $\mathrm{C}$ is the contentious area also discussed as part of our GPS collar component of this paper. This is the area of the reserve where there is among the narrowest width of buffer zone $(100 \mathrm{~m})$ and one in which a narrow strip of core zone extends out between surrounding human establishments. Area $\mathrm{C}$ also partly overlaps with an existing grazing area, such that there should be further discussion to determine the exact location where the boundary should be drawn.

We also identified approximately $178 \mathrm{~km}^{2}$ of current buffer zone in the reserve that is outside of existing human establishment but also inside of areas identified as having panda presence (focal buffer zone, Fig. 6). Certainly, some of this area should remain as buffer zone, especially when adjacent to an experimental zone. However, of note in Fig. 6 is the large width of buffer zone in some places, extending up to $4 \mathrm{~km}$ away from the nearest experimental zone. We identify two areas in Fig. 6 (D and E) where consideration should be made for extending the core zone to account for panda presence. In addition, considering the strong presence of pandas in area $\mathrm{F}$ (an area which is currently entirely buffer zone), we propose that discussion should be initiated to create a new region of core zone here.
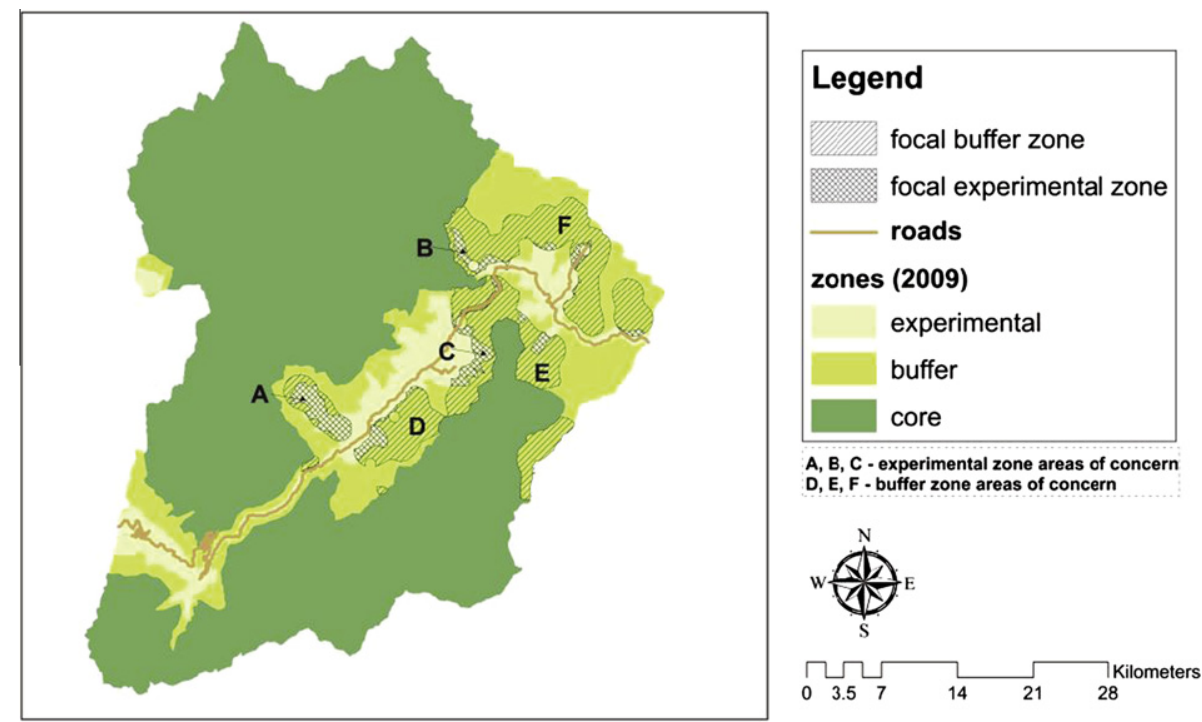

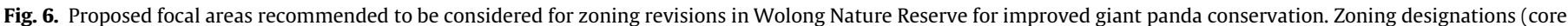

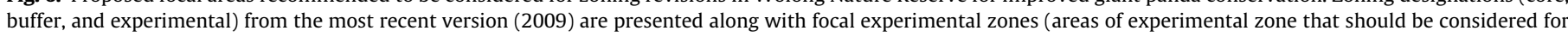

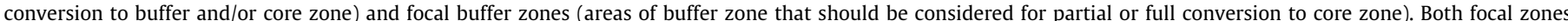

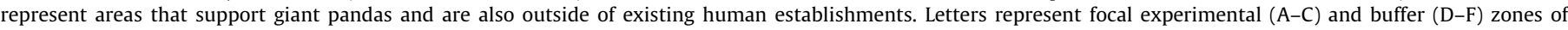
particular importance that are recommended for revision to better protect the panda population. 


\section{Discussion}

\subsection{Efficacy of zoning in Wolong}

This study showed that the design of zoning designations put in place in Wolong Nature Reserve for multiple-use management could be improved with respect to the goal of protecting the endangered giant panda population. All three approaches we used to analyze the distribution of giant pandas and their habitat with respect to the zones suggested that the buffer zone (and some areas of the experimental zone) serves an important role in supporting the giant panda population. However, the regulations on the types and degrees of human activities that are allowed in the buffer zones are not clearly defined in the management and policy arenas at the national level in China (Liu and Li, 2008). Thus, there is a degree of vulnerability of the panda population when it is not limited to the fully protected core zone.

It is important to underline that giant pandas are just one species of the thousands present in this reserve. Although the giant panda is often a considerable focus for management and policy making, further research is required to investigate the efficacy of zoning for other plant and animal species, most of which have insufficient data available to draw conclusions. It is worth noting, however, that rare and endangered plant and animal species inhabiting the high-elevation (above tree-line) areas in the reserve appear to be well contained in the core zone of this zoning scheme, including the snow leopard (Uncia uncial), blue sheep (Pseudois nayaur), and red poppywort (Meconopsis punicea) (Schaller et al., 1985; State Forestry Administration, 1999; Wolong Nature Reserve Management, 1987). On the other hand, other rare and endangered species that have a higher degree of overlap with the giant panda's forest habitat may be facing similar risks with respect to zoning, including the Asiatic black bear (Urus thibetanus), red panda (Ailurus fulgens), dove tree (Davidia involucrata) and the Katsura tree (Cercidiphyllum japonicum) (Schaller et al., 1985; Wolong Nature Reserve Management, 1987).

Another question that is important to address concerns the issue of efficacy of zoning designation with respect to enforcing restrictions on human activity across zones. Perhaps the most positive outcome of the zoning scheme from the perspective of biodiversity conservation is that no new houses or roads were built outside of the experimental zone after the zoning designation was put in place. One could argue that it would not be feasible or practical to construct roads and houses in the high elevation parts of the core zone, regardless of whether a zoning designation prohibited such construction. However, several areas of buffer zone and some parts of the core zone (e.g., areas surrounding $C$ and $\mathrm{D}$ in Fig. 6) are at low elevations and in close proximity to existing human establishments, meaning that further human development would be conceivable in these areas if it were not prohibited by the zoning scheme.

It is also promising that the majority of tourism infrastructure was contained within the experimental zone. However, the efficacy of the zoning designation was put in question with the extension of the experimental zone to allow for a new major tourism attraction in one area. This revision was balanced out by returning one undeveloped area to core zone in another part of the reserve, but it is debatable as to whether those areas are of the same value for panda conservation. This is an issue that is by no means limited to Wolong, as several other nature reserves in China have put forth requests for zoning revisions to allow for future development (Hubei Environmental Protection Agency, 2008). Such a practice reflects an insufficiency of the policy governing the rules for zoning designation and readjustment at the national level, which could stand to threaten the efficacy of this tool for conservation.
Another important finding of this study was that zoning was largely ineffective in regulating livestock grazing. While the livestock issue warrants further study at a larger scale, the three herds we monitored in this study, and particularly Herd 1 which roamed freely across all three zones, provided revealing information. Livestock have significant impacts on panda habitat through their destruction of bamboo, the panda's main food source (Ran, 2003) and have been identified as one of the most significant threats to panda habitat across their entire range in the latest National Giant Panda Census (State Forestry Administration, 2006). However, there is currently no policy in place that specifically tackles this issue. Livestock are difficult to regulate on the ground because they are less visible than a tourism facility or a house. But on the other hand, livestock are domesticated and can be effectively managed using clear policy frameworks (unlike a wild pest or invasive species). Our study indicates that zoning is apparently ineffective at containing livestock and thus other conservation measures, such as conservation incentive programs (similar to the existing Natural Forest Conservation Program, NFCP (Liu et al., 2008)), should be considered when addressing this issue. Strategies that impose steep penalties such as imprisonment have been successful at regulating activities such as poaching of giant pandas (Lü and Kemf, 2001), but may not be realistic or ethical when projected onto livestock grazing.

It is also important to note that the core and buffer zones did appear to experience more relative improvement in forest cover than the experimental zone, given historical levels of forest cover estimated in 1974. However, such improvements cannot be fully attributed to the zoning scheme and may instead be more closely linked to other conservation policies such as the NFCP (Viña et al., 2011). This conservation payment program was implemented around the same time as the zoning scheme and may have more directly impacted forest cover change by altering the behavior of individuals inhabiting local households as they responded to changes in ecosystem services (e.g., fuelwood availability) and land use dynamics (e.g., cropland and transportation changes) (Chen et al., 2009; Viña et al., 2011). Further studies should strive to study the complex interactions between these conservation policies and that of zoning.

To better understand the inherent complexities in such a system, it is instructive to consider it as a Coupled Human and Natural System (CHANS) (Liu et al., 2007a,b). Zoning informs this paradigm by highlighting the extent to which regulatory designations are difficult to design on the ground when the human and natural components of a system interact and cannot be completely separated into distinct, exclusive zones. The ideal core zone would be designed just for biodiversity conservation alone and the ideal experimental zone for human activities alone, with the buffer zone representing an area where there would be some overlap between the two systems. However, in reality, we found that large parts of the core zone were uninhabitable by both humans and pandas because they were located above the tree line and lacking in key resources that both depend upon. At the same time, parts of the experimental zone were ideal for both humans and pandas and were places where both interacted across shared space (such as with livestock and pandas both sharing the same $3-5 \mathrm{~km}^{2}$ area or with pandas inhabiting areas close to tourism facilities, roads, or houses).

One could argue that the revised zoning designations we propose in this study have little value when considering the formidable challenges with enforcement of human activities across zones. While we recognize and discuss such challenges in Section 4.2, we do not believe that these challenges should warrant discounting the value of zoning schemes. Instead, we believe that the successes we documented here with the exclusion of development in the 
core zone mean that efforts should be made toward improving the design. We hope that the areas of buffer and experimental zone identified in this study to be considered for revision can help aid in pinpointing locations for future panda conservation focus. This is particularly evident when considering area $\mathrm{F}$ in Fig. 6. The zoning in this area was recently amended to allow for the development of a tourism facility. This amendment comprises a large tract of buffer zone that appears to support a large number of pandas (according to the most recent panda census). It is located in close proximity to a proposed linkage area identified by Xu et al. (2006) to be ideal for establishing a corridor to help decrease fragmentation between Wolong and neighboring panda habitat outside the reserve. Such corridors are important, considering that population viability analyses on the species suggest that dispersal among fragmented subpopulations is crucial for long-term survival (Zhou and Pan, 1997; Zhu et al., 2010). That being said, we do not suggest that our identified focus areas for zoning revision comprise an ideal design. In fact, further groundwork should be done to obtain a more detailed picture of the costs and benefits to both humans and pandas for zoning adjustment at each specific site.

\subsection{Zoning as a conservation tool}

Considering these findings, it is important to take a step back to ask the question of the role of zoning in protected areas in China (and across the world) while recognizing both its strengths and limitations. The challenges in zoning designations are unlikely unique to Wolong. In fact, Wolong is regarded by many to be a flagship nature reserve and one that has had measurable success in conservation and management (State Forestry Administration, 2006), while the challenges with zoning appear to be more severe in many other nature reserves in China (Liu and $\mathrm{Li}, 2008$ ).

The strengths of zoning lie in its ability to shape development of tourism and transportation infrastructure at the hands of development companies. The challenge here is to ensure that biodiversity is adequately accounted for in the original design of zoning boundaries when it has the tendency to be ignored (Liu and Li, 2008). It is also important to ensure that adjustments of boundaries are performed with a set of well-defined rules and regulations that consider both conservation and development needs, as opposed to simply re-drawing the lines when development is desired. In Wolong, for example, despite revisions performed to account for the construction of tourism facilities, there have been no apparent attempts to revisit the zoning scheme in a corresponding way with respect to biodiversity protection.

The biggest limitation of zoning schemes is that they are inherently difficult to enforce on the ground when it comes to individual animal and human behaviors because it may be difficult to draw "lines in the sand" where one zone begins and the another ends. While buffer zones can help in this regard, by serving as "fuzzy" boundaries, their effectiveness is limited when there are no physical boundaries separating zones. Animals and plants certainly do not observe the designations, yet creating man-made boundaries (e.g., fences) is usually not practical. Humans may also not be aware of the designations, considering that some of our social surveys in Wolong with local residents revealed that many of them were unaware of other recent government policies (He et al., 2009). This observation reiterates the central message of the CHANS framework, which is that humans and natural systems are inherently coupled, such that simply drawing boundaries on a map to attempt to extricate them is difficult.

Ethical issues also come into play when considering the prospect of completely barring local residents (who are often economically poor) from using vital natural resources in their neighborhoods (Melick et al., 2007). Therefore, conservation payment programs that are currently in place in nature reserves of
China such as the NFCP and the GTGP, which provide monetary subsidies to residents for their participation in conservation programs may be more suitable for regulating these types of human activities (Liu et al., 2008). Thus, it is important for reserve managers to further strengthen these types of programs when the zoning scheme itself may not be adequately addressing all biodiversity goals.

In conclusion, zoning is one of many tools that are not a "cure all' for conservation problems. No one policy can address all complexities of conservation challenges in a human-dominated world; rather a portfolio of different policies is needed. In our study area, zoning has proven effective as a tool in itself by preventing haphazard human development throughout an area of high biodiversity and one that supports a conservation icon, the giant panda. However, it is also important to recognize where zoning falls short as a method for achieving conservation goals (in our case with managing livestock and when readjustment was not clearly regulated), such that other methods may be needed to fill in the gaps.

In order for zoning to be effective, it must be implemented in a transparent way and in a way that allows for regulated and sound adjustments to be made in response to changing conditions in today's human-dominated systems (Geneletti and van Duren, 2008; Villa et al., 2002). It is especially important to adopt an adaptive approach when considering the implications of climate change, a phenomenon that can cause species' ranges to shift outside of their inscribed management zones and thus require revisions to management plans (Hannah et al., 2007; Murphy et al., 2010). The complexity of interacting human and natural components in our system underscores the importance of such procedures for effective zoning with respect to multiple-use systems. Considering these challenges, we advocate for a CHANS approach to investigating the efficacy of zoning designations throughout nature reserves worldwide in order to better understand both human and natural factors that govern the success of this measure within the context of broader conservation initiatives.

\section{Acknowledgements}

We gratefully acknowledge the Wolong Nature Reserve administration for their ongoing support for this and other studies. We thank the veterinary and research staff at the China Conservation and Research Center for the Giant Panda (CCRCGP) for their assistance with this work, including Rengui $\mathrm{Li}$ and Dian Liu. We also thank Shumin Fan and Wenbing Yang for their dedicated efforts in performing field work. We thank the National Science Foundation (NSF), the National Aeronautics and Space Administration (NASA), the Michigan State University Distinguished Fellowship Program, the William W. and Evelyn M. Taylor International Engagement Fellowship Program, the National Natural Science Foundation of China (40901289), and the State Key Laboratory of Urban and Regional Ecology, Research Center for Eco-Environmental Sciences, Chinese Academy of Sciences for providing funding for this work.

\section{References}

Agardy, T., 2010. Ocean Zoning - Making Marine Management More Effective. Earthscan, London, UK.

Andam, K.S., Ferraro, P.J., Pfaff, A., Sanchez-Azofeifa, G.A., Robalino, J.A., 2008 Measuring the effectiveness of protected area networks in reducing deforestation. Proceedings of the National Academy of Sciences 105, 1608916094.

Babcock, R.C., Shears, N.T., Alcala, A.C., Barrett, N.S., Edgar, G.J., Lafferty, K.D. McClanahan, T.R., Russ, G.R., 2010. Decadal trends in marine reserves reveal differential rates of change in direct and indirect effects. Proceedings of the National Academy of Sciences 107, 18256-18261.

Bailey, T.C., Gatrell, A.C., 1995. Interactive Spatial Data Analysis. Prentice Hall, Harlow, England. 
Barnosky, A.D., Matzke, N., Tomiya, S., Wogan, G.O.U., Swartz, B., Quental, T.B. Marshall, C., McGuire, J.L., Lindsey, E.L., Maguire, K.C., Mersey, B., Ferrer, E.A., 2011. Has the Earth's sixth mass extinction already arrived? Nature 471, 51-57.

Batisse, M., 1997. Biosphere reserves: a challenge for biodiversity conservation and regional development. Environment: Science and Policy for Sustainable Development 39, 6-33.

Chen, X., Lupi, F., He, G., Ouyang, Z., Liu, J., 2009. Factors affecting land reconversion plans following a payment for ecosystem service program. Biological Conservation 142, 1740-1747.

DeFries, R., Hansen, A., Turner, B.L., Reid, R., Liu, J.G., 2007. Land use change around protected areas: management to balance human needs and ecological function. Ecological Applications 17, 1031-1038.

Diamond, J., 2005. Collapse: How Societies Choose to Fail or Succeed. Penguin Books, New York, NY.

Eigenbrod, F., Anderson, B.J., Armsworth, P.R., Heinemeyer, A., Jackson, S.F., Parnell, M., Thomas, C.D., Gaston, K.J., 2009. Ecosystem service benefits of contrasting conservation strategies in a human-dominated region. Proceedings of the Royal Society of London, Series B: Biological Sciences 276, 2903-2911.

ESRI, 2006. ArcGIS Desktop. Version 9.2. ESRI Inc., Redlands, California, USA

Geneletti, D., van Duren, I., 2008. Protected area zoning for conservation and use: a combination of spatial multicriteria and multiobjective evaluation. Landscape and Urban Planning 85, 97-110.

Ghimire, K.B., 1997. Conservation and social development: an assessment of Wolong and other panda reserves in China. In: Ghimire, K.B., Pimbert, M.P. (Eds.), Environmental Politics and Impacts of National Parks and Protected Areas. Earthscan Publications, London, UK, pp. 187-213.

Gonzales, E.K., Arcese, P., Schulz, R., Bunnell, F.L., 2003. Strategic reserve design in the central coast of British Columbia: integrating ecological and industrial goals. Canadian Journal of Forest Research-Revue Canadienne De Recherche Forestiere 33, 2129-2140.

Hannah, L., Midgley, G., Andelman, S., Araujo, M., Hughes, G., Martinez-Meyer, E., Pearson, R., Williams, P., 2007. Protected area needs in a changing climate. Frontiers in Ecology and the Environment 5, 131-138.

Harris, R.B., 2008. Wildlife Conservation in China - Preserving the Habitat of China's Wild West. M.E. Sharpe, Inc., Armonk, New York

He, G., Chen, X., Bearer, S., Colunga, M., Mertig, A., An, L., Zhou, S., Linderman, M., Ouyang, Z., Gage, S., Li, S., Liu, J., 2009. Spatial and temporal patterns of fuelwood collection in Wolong Nature Reserve: implications for panda conservation. Landscape and Urban Planning 92, 1-9.

Hjortso, C.N., Straede, S., Helles, F., 2006. Applying multi-criteria decision-making to protected areas and buffer zone management: a case study in the Royal Chitwan National Park, Nepal. Journal of Forest Economics 12, 91-108.

Hubei Environmental Protection Agency, 2008. Activities of Seven Environmental Protection Departments for Strengthening Protected Area Management. <http://www.hbepb.gov.cn/hbyw/stbh/zrbhq/200809/ t20080922 14775.html>.

Jenkins, C.N., Joppa, L., 2009. Expansion of the global terrestrial protected area system. Biological Conservation 142, 2166-2174.

Jim, C.Y., Xu, S.S.W., 2002. Stifled stakeholders and subdued participation: interpreting local responses toward Shimentai Nature Reserve in South China. Environmental Management 30, 327-341

Jim, C.Y., Xu, S.S.W., 2004. Recent protected-area designation in China: an evaluation of administrative and statutory procedures. The Geographical Journal 170, 39-50.

Kenchington, R., Day, J., 2011. Zoning, a fundamental cornerstone of effective Marine Spatial Planning: lessons learnt from the Great Barrier Reef, Australia. Journal of Coastal Conservation 15, 271-278.

Leakey, R.E., Lewin, R., 1996. The Sixth Extinction: Patterns of Life and the Future of Humankind. Anchor Books, New York.

Linderman, M.A., An, L., Bearer, S., He, G., Ouyang, Z., Liu, J., 2005. Modeling the spatio-temporal dynamics and interactions of households, landscapes, and giant panda habitat. Ecological Modelling 183, 47-65.

Liu, X., Li, J., 2008. Scientific solutions for the functional zoning of nature reserves in China. Ecological Modelling 215, 237-246.

Liu, J., Raven, P., 2010. China's environmental challenges and implications for the world. Critical Reviews in Environmental Science and Technology 40, 823-851.

Liu, J., Ouyang, Z., Taylor, W.W., Groop, R., Tan, K., Zhang, H., 1999. A framework for evaluating the effects of human factors on wildlife habitat: the case of giant pandas. Conservation Biology 13, 1360-1370.

Liu, J., Linderman, M., Ouyang, Z., An, L., Yang, J., Zhang, H., 2001. Ecologica degradation in protected areas: the case of Wolong Nature Reserve for giant pandas. Science 292, 98-101.

Liu, J., Dietz, T., Carpenter, S.R., Alberti, M., Folke, C., Moran, E., Pell, A.N., Deadman, P., Kratz, T., Lubchenco, J., Ostrom, E., Ouyang, Z., Provencher, W., Redman, C.L., Schneider, S.H., Taylor, W.W., 2007a. Complexity of coupled human and natural systems. Science 317, 1513-1516.

Liu, J., Dietz, T., Carpenter, S.R., Folke, C., Alberti, M., Redman, C.L., Schneider, S.H. Ostrom, E., Pell, A.N., Lubchenco, J., Taylor, W.W., Ouyang, Z., Deadman, P., Kratz, T., Provencher, W., 2007b. Coupled human and natural systems. AMBIO: A Journal of the Human Environment 36, 639-649.

Liu, J., Li, S., Ouyang, Z., Tam, C., Chen, X., 2008. Ecological and socioeconomic effects of China's policies for ecosystem services. Proceedings of the National Academy of Sciences 105, 9477-9482.
Lü, Z., Kemf, E., 2001. Giant Pandas in the Wild: a WWF Species Status Report. WWF International, Gland, Switzerland, p. 24

Mackinnon, J., 2008. Species richness and adaptive capacity in animal communities: lessons from China. Integrative Zoology 3, 95-100.

McNeely, J.A., 1994. Protected areas for the 21st century: working to provide benefits to society. Biodiversity and Conservation 3, 390-405.

Melick, D., Yang, X., Xu, J., 2007. Seeing the wood for the trees: how conservation policies can place greater pressure on village forests in southwest China. Biodiversity and Conservation 16, 1959-1971.

Ministry of Forestry, 1998. Wolong Nature Reserve Master Plan, Beijing, China (in Chinese).

Murphy, K., Huettmann, F., Fresco, N., Morton, J., 2010. Connecting Alaska Landscapes into the Future. US Fish and Wildlife Service, and the University of Alaska. <http://www.snap.uaf.edu/downloads/connecting-alaskalandscapes-future>.

Naughton-Treves, L., Holland, M.B., Brandon, K., 2005. The role of protected areas in conserving biodiversity and sustaining local livelihoods. Annual Review of Environmental Resources 30, 219-252.

Pimm, S.L., Russell, G.J., Gittleman, J.L., Brooks, T.M., 1995. The future of biodiversity. Science 269, 347-350

Ran, J., 2003. Habitat selection by giant pandas and grazing livestock in the Xiaoxiangling Mountains of Sichuan Province. Journal of Sun Yatsen University Social Science Edition 23, 2253-2259 (in Chinese).

Remis, M.J., Kpanou, J.B., 2011. Primate and ungulate abundance in response to multi-use zoning and human extractive activities in a Central African Reserve. African Journal of Ecology 49, 70-80.

Sabatini, M.D.C., Verdiell, A., Rodriguez Iglesias, R.M., Vidal, M., 2007. A quantitative method for zoning of protected areas and its spatial ecological implications. Journal of Environmental Management 83, 198-206.

Salomon, A.K., Waller, N.P., McIlhagga, C., Yung, R.L., Walters, C., 2002. Modeling the trophic effects of marine protected area zoning policies: a case study. Aquatic Ecology 36, 85-95.

Schaller, G.B., Hu, J., Pan, W., Zhu, J., 1985. The Giant Pandas of Wolong. University of Chicago Press, Chicago, Illinois, USA.

State Forestry Administration, 1999. National Focal Protected Wild Plant List of China (in Chinese)

State Forestry Administration, 2006. The 3rd National Survey Report on Giant Panda in China. Science Publisher, Beijing, China (in Chinese)

Tan, Y., Ouyang, Z., Zhang, H., 1995. Spatial characteristics of biodiversity in Wolong Nature Reserve. China's Biosphere Reserve 3, 19-24 (in Chinese).

The State Council, 1994. Bylaws of Nature Reserves in the People's Republic of China (in Chinese)

Villa, F., Tunesi, L., Agardy, T., 2002. Zoning marine protected areas through spatial multiple-criteria analysis: the case of the Asinara Island National Marine Reserve of Italy. Conservation Biology 16, 515-526.

Viña, A., Bearer, S., Chen, X., Hu, G., Linderman, M., An, L., Zhang, H., Ouyang, Z., Liu, J. 2007. Temporal changes in giant panda habitat connectivity across boundaries of Wolong Nature Reserve, China. Ecological Applications 17, 1019-1030.

Viña, A., Tuanmu, M.-N., Xu, W., Li, Y., Ouyang, Z., DeFries, R., Liu, J., 2010. Rangewide analysis of wildlife habitat: implications for conservation. Biological Conservation 143, 1960-1969.

Viña, A., Chen, X.D., McConnell, W.J., Liu, W., Xu, W.H., Ouyang, Z.Y., Zhang, H.M., Liu, J.G., 2011. Effects of natural disasters on conservation policies: the case of the 2008 Wenchuan Earthquake, China. Ambio 40, 274-284.

Watts, M.E., Ball, I.R., Stewart, R.S., Klein, C.J., Wilson, K., Steinback, C., Lourival, R., Kircher, L., Possingham, H.P., 2009. Marxan with Zones: software for optimal conservation based land- and sea-use zoning. Environmental Modelling and Software 24, 1513-1521.

WDPA, 2009. World Database on Protected Areas (WDPA) Annual Release 2009, February 2009. <http://www.wdpa.org/>

Wittemyer, G., Elsen, P., Bean, W.T., Burton, A.C.O., Brashares, J.S., 2008. Accelerated human population growth at protected area edges. Science 321, 123-126.

Wolong Nature Reserve, 2005. History of the Development of Wolong Nature Reserve. Sichuan Science Publisher, Chengdu, China (in Chinese).

Wolong Nature Reserve Management, 1987. Wolong Vegetation and Resource Plants. Sichuan Publishing House of Science and Technology, Sichuan, China (in Chinese).

Xiao, J., Xu, W.H., Kang, D.W., Li, J.Q., 2011. Nature reserve group planning for conservation of giant pandas in North Minshan, China. Journal for Nature Conservation 19, 209-214.

Xu, W., Ouyang, Z., Vina, A., Zheng, H., Liu, J., Xiao, Y., 2006. Designing a conservation plan for protecting the habitat for giant pandas in the Qionglai mountain range, China. Diversity and Distributions 12, 610-619.

Yu, G.-Z., Jiang, Z.-G., 2003. Buffer zones: pattern, function and design principles. Biodiversity Science 11, 256-261 (in Chinese)

Zhang, H., Li, D., Wei, R., Tang, C., Tu, J., 1997. Advances in conservation and studies on reproductivity of giant pandas in Wolong. Sichuan Journal of Zoology 16, $31-$ 33 (in Chinese).

Zhou, Z., Pan, W., 1997. Analysis of the viability of a giant panda population. Journal of Applied Ecology 34, 363-374.

Zhu, L., Zhan, X., Meng, T., Zhang, S., Wei, F., 2010. Landscape features influence gene flow as measured by cost-distance and genetic analyses: a case study for giant pandas in the Daxiangling and Xiaoxiangling Mountains. BMC Genetics 11, 72. 